\title{
Socio Economic and Maternal Reproductive factors affecting Low Birth Weight Babies in Central Nepal
}

\author{
Shrestha $\mathbf{M}^{1}$, Gupta $\mathbf{S K}^{2}$, Sarmah BK${ }^{3}$, Baidya $\mathbf{M}^{4}$
}

${ }^{1}$ Dr. Manju Shrestha, MBBS. MD, Department of Paediatrics, Shree Birendra Hospital, Chhauni, Kathamndu, Nepal, ${ }^{2}$ Dr. Sweta Kumari Gupta, MBBS, MD, Assistant Professor, Department of Paediatrics, College of Medical sciences, Bharatpur, Nepal. ${ }^{3}$ Dr. Bhawani Kant Sharmah, MBBS. MD, Head of department, Department of Paediatrics, College of Medical sciences, Bharatpur, Nepal. ${ }^{4}$ Manish Baidya, PhD Research Fellow, Kathmandu University, Dhulikhel, Kavre, Nepal.

\section{Address for correspondence: \\ Dr. Manju Shrestha \\ Department of Paediatrics \\ Shree Birendra Hospital \\ Chhauni, Nepal \\ Tel No; +9779841652845 \\ E-mail: drmanjustha@gmail.com}

Acknowledgements: We express our profound gratitude to College of Medical Sciences Bharatpur, Chitwan, Nepal for providing research grant and technical support for the study.

Funding: Nil

Conflict of Interest: This study has been taken as a part from the compulsory submission of MD thesis work submitted to the Kathmandu University, Dhulikhel, Nepal.

Permission from IRB: Yes

Ethical dilemmas faced during study: No

\section{How to cite}

Shrestha M, Gupta SK, Sarmah BK, Baidya M. Socio Economic and Maternal Reproductive factors affecting Low Birth Weight Babies in Central Nepal. J Nepal Paediatr Soc 2016;36(3):277-283.

doi: http://dx.doi.org/10.3126/jnps.v36i3.16394

This work is licensed under a Creative Commons Attribution 3.0 License.

\begin{abstract}
Introduction: Low Birth weight is one of the most sensitive and reliable predictors of health and also an essential determinant of mortality, morbidity and disability in infancy and childhood. Globally, about one sixth of all newborns are low birth weight (LBW $<2500$ grams), which is the single most important underlying risk factors for neonatal deaths. It is estimated that 18 million babies are born with Low Birth Weight and half of them are born in south Asia.Over three quarters of newborns death in Nepal occur in LBW babies. The estimates of prevalence of LBW in Nepal have ranged from $14 \%$ in community based studies to $32 \%$ in hospital based ones, overall being $27 \%$. Objectives were to study the various socioeconomic and maternal reproductive factors related to low birth weight babies in Central regional part of Nepal.Material and Methods: Cross-sectional and observational study was undertaken from October 2012 to September 2014 comprising of 350 singleton live born baby admitted in NICU of Tertiary Care Teaching Hospital, Chitwan. Results: The common risks factors for LBW were significantly associated with low socio- economic status, maternal age, maternal education, occupation of mother, maternal smoking, maternal alcohol intake, number of ANC visit with significant $p$-value of $<0.05$. Conclusion: LBW mostly associated with maternal factors can be addressed directly by improving the socioeconomic factors (maternal age, educational level and economic status) and health status of pregnant women by supplementations, family planning services and female education.
\end{abstract}

Key words: Low Birth Weight, Neonate, Maternal, Socioeconomic.

\section{Introduction}

Birth weight is the first weight of the newborn obtained after birth. Birth weight should preferably be measured within the first hour of life for live births, before significant postnatal weight loss has occurred. In 1976, the $29^{\text {th }}$ World Health Assembly agreed on the following definition of low birth weight that "Low birth weight is a weight at birth of less than $2500 \mathrm{gms}$ (up to and including 2499) irrespective of gestational age". This replaced the earlier definition of $2500 \mathrm{gms}$ or less ${ }^{1,2,3,4,5}$. 
Birth weight is an important indicator of child survival. Appropriate and timely care of a new born especially if he/she is born with low birth weight is important but this is difficult in developing countries since most of the deliveries are conducted at home where adequate facilities to weigh a newborn do not exist. Although these low birth weight babies account for $14 \%$ of the children born, they account for $60-80 \%$ of neonatal deaths $s^{6,7,8,9}$.

Low birth weight has been used as an important public health indicator. The mortality rate rapidly increases as the birth weight decrease and most of infants weighing 1000 grams or less ${ }^{10}$. The high prevalence of LBW contributes to the high perinatal, neonatal and infant mortality and is a common feature of many developing countries, especially in South Asia where the incidence ranges from $20-30 \%$. The estimates of prevalence of LBW in Nepal have ranged from $14 \%$ in community based studies to $32 \%$ in hospital based ones, overall being $27 \%^{11}$. However, recent reports show that the percentage of children with low birth weight varies from 11 percent in the mountains to 13 percent in the hills and 16 percent in Terai, highest being in Far western region and particularly in far western Terai- sub region (28\%) $12,13,14,15$. In developing countries, there are more babies with poorer growth having the risk of more diabetic, hypertensive and coronary heart disease patients in later life. Moreover, with demographic transition through increased life expectancy at birth, these countries are going to face more burdens of chronic diseases $16,17,18,19$.

The biological processes that affect the fetus in utero are related to the mother's physiology, including her nutrition (mother's weight before pregnancy and history of having newborns with LBW), exercise, infection and consumption of alcohol, tobacco, teenage pregnancy, poor antenatal care, education other drugs ${ }^{20,21,22,23}$. Four antenatal visits have been recommended byWHO technical group committee for women with normal pregnancy. The socio-economic factors associated with LBW are income, level of education in the mother and other family members, occupation of the mother, household leadership and gender differences related to roles within the family $24,25,26,27,28,29,30$.

This study was undertaken with an aim to find out the risks factors of LBW babies, so that in future the mortality, morbidity and the burden of chronic disease can be reduced from the developing countries like ours.

Objective: To study the socioeconomic and maternal reproductive factors related to Low Birth Weight (LBW) of babies delivered in central regional part of Nepal.

\section{Material and Methods}

This study was hospital based, cross-sectional and observational study conducted in a central regional tertiary care Teaching hospital of Nepal. Data were collected prospectively from October 2012 to September 2014 for a period of two years. Consent were taken from every mother before interview and the weight of the newborn was taken within the 24 hours of delivery and each questionnaire was completed. Record review format was used for reviewing antenatal care cards. By taking confidence interval of $95 \%$ and permissible error of 0.05 and " $p$ " as 0.28 the number of sample size was 350 .

Mothers along with single live newborn delivered in hospital were included in the study. Mothers who had given multiple births or still birth baby and mother having disease during pregnancy and refusing to give consent were excluded from the study.

Data was compiled in Statistical Package for Social Sciences (SPSS) software version 20.0 and analyzed. Simple descriptive analysis, chi-square test was used to determine the risk factors. Logistic regression analysis was used to assess relationship between LBW and maternal risk factors. Logistic regression results were reported as odds ratio and $95 \%$ confidence interval along with $p$-value.

Permission from the Institutional Review Board was taken to do the study.

\section{Results}

A total of 1206 birth occurred during the study period, of which 350 met the inclusion criteria. Out of which 116 were LBW and 234 were normal birth weight(NBW). Hence, the prevalence of LBW in this present study was found to be $33.1 \%$. Overall mean birth weight was found to be $2.65+0.536 \mathrm{~kg}$. Out of total, $33.1 \%$ newborns were weighting less than $2500 \mathrm{gms}$ and mean birth weight was $1.96+0.412$ (Table no. 1).

Table 2 and 3 depicts the results of univariate analysis of maternal factors associated with LBW. The factors associated with LBW included age, education, family members, gravida, antenatal care smoking and alcohol. The following variables were found insignificant: religion, residence, occupation, family type, birth to conception interval, still birth, abortion, death of previous children, and gestational age at $1^{\text {st }} \mathrm{ANC}$ visit. LBW was mostly seen $(37 \%)$ in mother of age group $<20$ and $\geq$ $35 \mathrm{yr}$ verses $14 \%$ LBW in babies delivered from mother of 20-30 years age group as depicted in figure 1. 
Multivariate analysis (multiple logistic regression) revealed that significant factors were age of the mother and education of mother and antenatal care and taking LBW as $0, N B W$ as 1 . The study showed correlation of LBW with the occupation of the mother (Fig. 2)

$81 \%$ of babies born to illiterate mothers and 52.5 $\%$ of babies born to housewives mothershad most of the LBW babies in comparison to mothers who had either government $7.7 \%$ or private job $12.8 \%$. Association between family members and birth weight was found to be significant. Proportion of LBW was maximum 94
$\%$ in mothers who didn't receive any antenatal care or less than 02 ANC before birth, followed by those who received antenatal care, in whom LBW proportion was $26.80 \%$.Out of 161 births, birth interval in relation to previous birth $\leq 24$ months was found to be in $66.1 \%$ and $14.3 \%$ found in mothers who had birth interval $\geq$ 24 months. Mothers who were smokers had $72.7 \%$ of LBW babies as compared with non-smokers who had $30.5 \%$ LBW babies. Mothers consuming alcohol had significantly higher no. of LBW babies (88.95\%) as compared to $31.7 \%$ in those who were non-alcoholic.

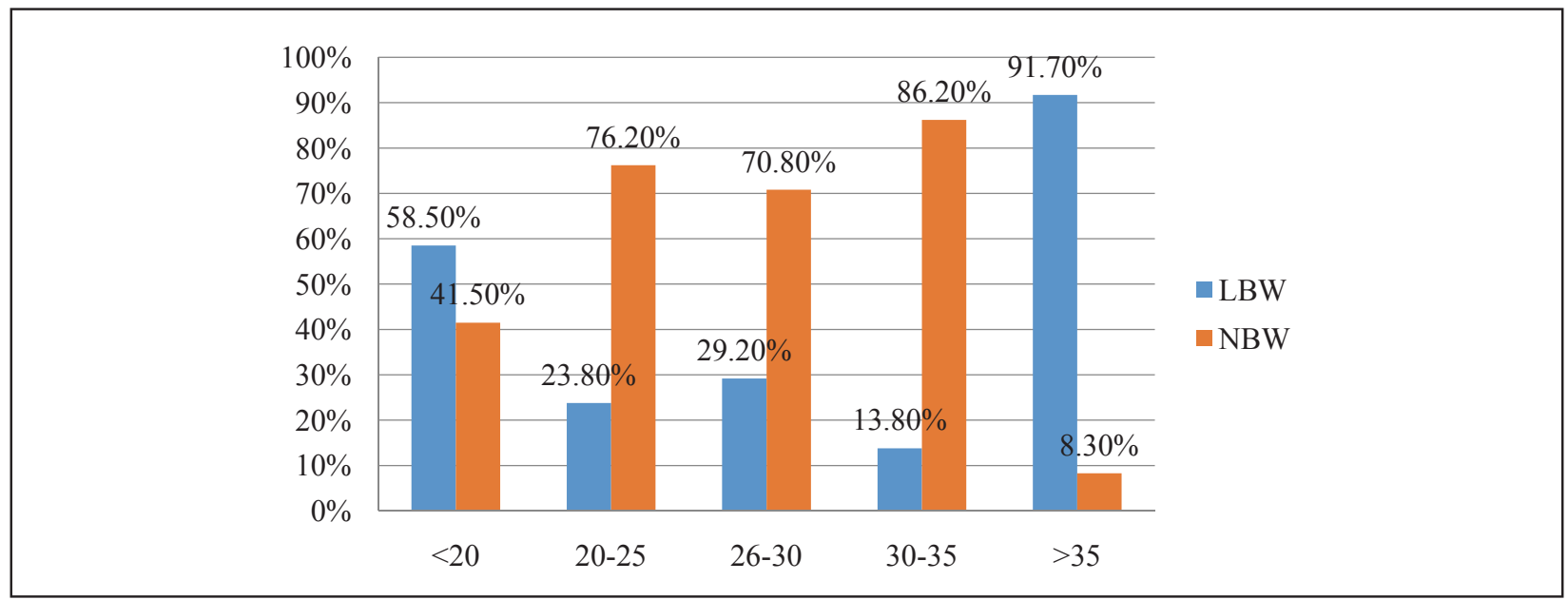

Fig 1: Showing comparison of birth weight with the age of mother

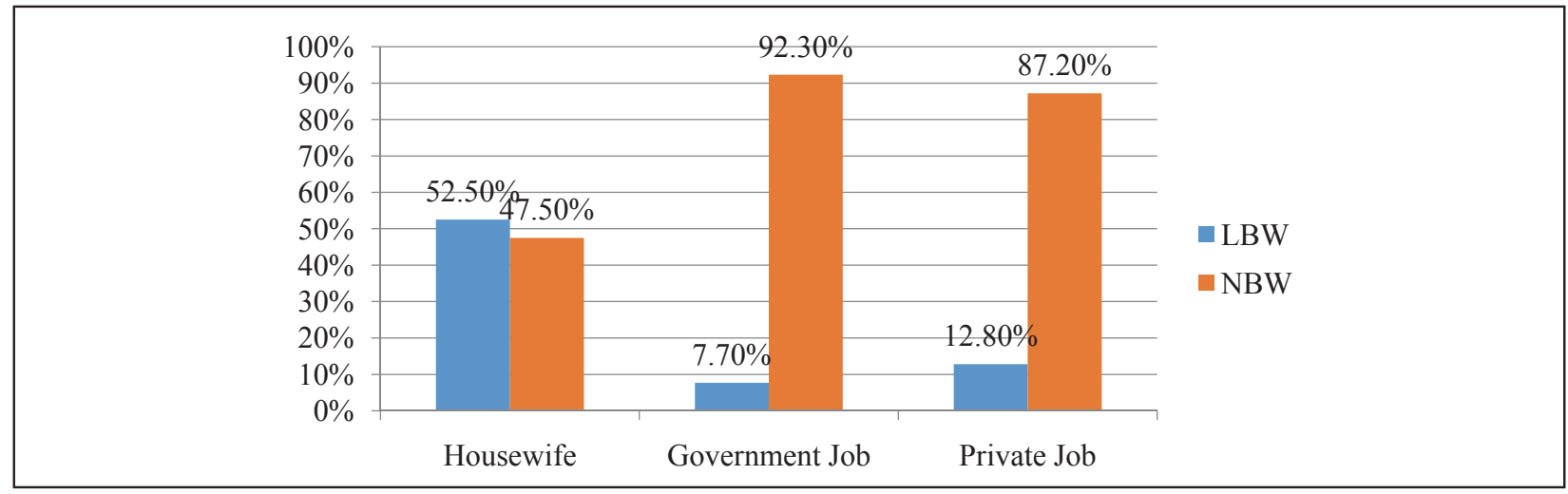

Fig 2: Showing The Comparison of Birth Weight with the Occupation of Mother

Table 1: No. of Newborns by their Birth Weight

\begin{tabular}{ccc}
\hline S. No & Birth weight of newborns in grams & No. of Newborns \\
\hline 1. & $<1000$ & 02 \\
\hline 2. & $1000-1499$ & 15 \\
\hline 3. & $1500-1999$ & 56 \\
\hline 4. & $2000-2499$ & 277 \\
\hline
\end{tabular}


Factors Affecting Low Birth Weight

Table 2: Effects of Maternal Factors on Birth Weight of Newborn

\begin{tabular}{|c|c|c|c|c|}
\hline Variables & LBW(N=116) & NBW N=234) & New Born Babies (350) & $p$-value \\
\hline \multicolumn{5}{|l|}{ Maternal age } \\
\hline$<20$ years & $48(58.5 \%)$ & $34(41.5 \%)$ & 82 & \multirow{5}{*}{$<0.05$} \\
\hline 20- 25 years & $34(23.8 \%)$ & $11(91.7 \%)$ & 143 & \\
\hline $26-30$ years & $14(29.2 \%)$ & $34(70.8 \%)$ & 48 & \\
\hline $30-35$ years & $9(13.8 \%)$ & $56(86.2 \%)$ & 65 & \\
\hline$>35$ years & $11(91.7 \%)$ & $1(8.3 \%)$ & 12 & \\
\hline \multicolumn{5}{|l|}{ Sex of child } \\
\hline Male & $61(30.5 \%)$ & $139(69.5 \%)$ & 200 & \multirow{2}{*}{ NS } \\
\hline Female & $55(36.7 \%)$ & $95(63.3 \%)$ & 150 & \\
\hline \multicolumn{5}{|l|}{ BMI of mother } \\
\hline$<18.5$ & $35(92.15 \%)$ & $3(7.9 \%)$ & 38 & \multirow{3}{*}{$<0.01$} \\
\hline $18.5-24.99$ & $74(30.8 \%)$ & $166(69.2 \%)$ & 240 & \\
\hline$>25$ & $7(9.7 \%)$ & $65(90.3 \%)$ & 72 & \\
\hline \multicolumn{5}{|l|}{ Gravida } \\
\hline $1^{\text {st }}$ & $62(33.5 \%)$ & $123(6.5 \%)$ & 185 & \multirow{3}{*}{$<0.01$} \\
\hline $2-3$ & $41(28.7 \%)$ & $102(71.3 \%)$ & 143 & \\
\hline$>4$ & $13(61.9 \%)$ & $9(38.1 \%)$ & 21 & \\
\hline \multicolumn{5}{|c|}{ Birth to Conception Interval } \\
\hline$>24$ Months & $15(14.3 \%)$ & $90(85.7 \%)$ & 105 & \multirow{2}{*}{ NS } \\
\hline$<24$ Months & $39(66.1 \%)$ & $20(33.9 \%)$ & 59 & \\
\hline \multicolumn{5}{|c|}{ Death of Previous Children } \\
\hline Yes & $15(60 \%)$ & $10(40 \%)$ & 25 & \multirow{2}{*}{ NS } \\
\hline No & $101(31.1 \%)$ & $224(68.9 \%)$ & 325 & \\
\hline \multicolumn{5}{|c|}{ Previous Abortion } \\
\hline Yes & $13(65 \%)$ & $7(35 \%)$ & 20 & \multirow{2}{*}{ NS } \\
\hline No & $103(31.2 \%)$ & $227(68.8 \%)$ & 330 & \\
\hline \multicolumn{5}{|c|}{ Previous Still Birth } \\
\hline Yes & $5(38.5 \%)$ & $8(61.5 \%)$ & 13 & \multirow{2}{*}{ NS } \\
\hline No & $111(32.9 \%)$ & $226(67.1 \%)$ & 337 & \\
\hline \multicolumn{5}{|c|}{ Total ANC Visits } \\
\hline$<2$ & $33(94.3 \%)$ & $2(5.7 \%)$ & 35 & \multirow{3}{*}{$<0.05$} \\
\hline $3-4$ & $64(26.8 \%)$ & $175(73.2 \%)$ & 239 & \\
\hline$>4$ & $19(25 \%)$ & $57(75 \%)$ & 76 & \\
\hline \multicolumn{5}{|l|}{ Diet } \\
\hline Vegetarian & $19(52.8 \%)$ & $17(47.2 \%)$ & 36 & \multirow[b]{2}{*}{ NS } \\
\hline Non Vegetarian & $97(30.9 \%)$ & $217(69.1 \%)$ & 313 & \\
\hline \multicolumn{5}{|c|}{ Folic acid and Iron tablets } \\
\hline Yes & $85(26.8 \%)$ & $232(73.2 \%)$ & 317 & \multirow{2}{*}{ NS } \\
\hline No & $31(93.9 \%)$ & $2(6.1 \%)$ & 33 & \\
\hline Gestational Ag & & & & \\
\hline $1^{\text {st }}$ Trimester & $40(17.2 \%)$ & $192(82.8 \%)$ & 232 & \\
\hline $2^{\text {nd }}$ Trimester & $57(57.6 \%)$ & $42(42.4 \%)$ & 99 & NS \\
\hline $3^{\text {rd }}$ Trimester & $19(100 \%)$ & 0 & 19 & \\
\hline Smoking & & & & \\
\hline Smoker & $16(72.7 \%)$ & $6(27.3 \%)$ & 22 & 505 \\
\hline Non Smoker & $100(30.5 \%)$ & $228(69.5 \%)$ & 323 & $<0.00$ \\
\hline Alcohol & & & & \\
\hline Alcoholic & $8(88.9 \%)$ & $1(11.1 \%)$ & 9 & $<0,05$ \\
\hline Non alcoholic & $108(31.7 \%)$ & $233(68.3 \%)$ & 341 & $<0.05$ \\
\hline
\end{tabular}

${ }^{*} N S=$ Not Significant, 'p'value $<0.05=$ Significant 
Table 3: Effects of Socioeconomic Factors on Birth Weight of Newborn

\begin{tabular}{|c|c|c|c|c|}
\hline Variables & Lbw ( $N=116)$ & Nbw $\mathrm{N}=234$ ) & New Born Babies (350) & $p$-value \\
\hline \multicolumn{5}{|l|}{ Religion } \\
\hline Hindu & $107(34.2 \%)$ & $206(65.8 \%)$ & 313 & \multirow{4}{*}{ NS } \\
\hline Muslim & $1(20.0 \%)$ & $4(80 \%)$ & 5 & \\
\hline Buddhist & $2(10.5 \%)$ & $17(89.5 \%)$ & 19 & \\
\hline Others & $6(46.2 \%)$ & $7(53.8 \%)$ & 13 & \\
\hline \multicolumn{5}{|l|}{ Education } \\
\hline No & $18(81.8 \%)$ & $4(18.2 \%)$ & 22 & \multirow{4}{*}{$<0.05$} \\
\hline Primary & $64(78 \%)$ & $18(22.0 \%)$ & 82 & \\
\hline Secondary & $22(28.6 \%)$ & $55(71.4 \%)$ & 77 & \\
\hline Higher & $12(7.1 \%)$ & $157(92.9 \%)$ & 169 & \\
\hline \multicolumn{5}{|c|}{ Occupation of mother } \\
\hline Housewife & $96(52.5 \%)$ & $87(47.5 \%)$ & 183 & \multirow{3}{*}{$<0.05$} \\
\hline Government Job & $2(7.7 \%)$ & $24(92.3 \%)$ & 26 & \\
\hline Private Job & $18(12.8 \%)$ & $123(87.2 \%)$ & 141 & \\
\hline \multicolumn{5}{|l|}{ Economic Status } \\
\hline Upper & $1(3.8 \%)$ & $25(96.2 \%)$ & 26 & \multirow{5}{*}{$<0.05$} \\
\hline Middle upper & $15(8.2 \%)$ & $167(1.8 \%)$ & 182 & \\
\hline Lower upper lower & $35(49.3 \%)$ & $36(50.7 \%)$ & 71 & \\
\hline Lower Middle & $58(90.6 \%)$ & $6(9.4 \%)$ & 64 & \\
\hline Lower & $7(100 \%)$ & 0 & 7 & \\
\hline \multicolumn{5}{|l|}{ Residence } \\
\hline Urban & $75(33.2 \%)$ & & 226 & \multirow{2}{*}{ NS } \\
\hline Rural & $41(31.1 \%)$ & $83(66.9 \%)$ & 124 & \\
\hline \multicolumn{5}{|l|}{ Family Type } \\
\hline Nuclear & $48(23.6 \%)$ & $155(76.4 \%)$ & 203 & \multirow{2}{*}{ NS } \\
\hline Joint & $68(46.3 \%)$ & $79(53.7 \%)$ & 147 & \\
\hline \multicolumn{5}{|l|}{ Gravida } \\
\hline $1^{\text {st }}$ & $62(33.5 \%)$ & $123(6.5 \%)$ & 185 & \multirow{3}{*}{$<0.01$} \\
\hline $2-3$ & $42(28.7 \%)$ & $102(71.3 \%)$ & 143 & \\
\hline$>4$ & $13(61.9 \%)$ & $9(38.1 \%)$ & 21 & \\
\hline \multicolumn{5}{|c|}{ Death of Previous Children } \\
\hline Yes & $15(60 \%)$ & $10(40 \%)$ & 25 & \multirow{2}{*}{ NS } \\
\hline No & $101(31.1 \%)$ & $224(68.9 \%)$ & 325 & \\
\hline
\end{tabular}

${ }^{*} \boldsymbol{N S}=$ Not Significant, ' $\boldsymbol{p}$ 'value $<0.05=$ Significant

\section{Discussion}

Birth weight, the weight of a neonate taken soon after birth, is the single most important indicator of neonatal outcome as well as overall health status later in life. In most of the third world countries including developing country like ours the incidence of low birth weight is high. The problem of low birth weight needs to be addressed on priority basis as children are the future of the country. Low birth weight neonates need special care since they have increased risk of mortality and long term morbidity.Globally, about one sixth of all newborns are low birth weight, which is the single most important underlying risk factors for neonatal deaths ${ }^{6}$. It is estimated that 18 million babies are born with LBW and half of them are born in south Asia.Over three quarters of newborns death in Nepal occur in LBW ${ }^{7}$. The high prevalence of LBW contributes to the high perinatal, neonatal and infant mortality and is a common feature of many developing countries, especially in South Asia where the incidence ranges from $20-30 \%{ }^{11}$. However, recent reports show that the percentage of children with low birth weight varies from 11 percent in the mountains to 13 percent in the hills and 16 percent in Terai, highest being in Far western region and particularly in far western Terai- sub region (28\%) of the country ${ }^{12}$. 
The study conducted to analyse various parameter causing and affecting low birth weight determined that preterm birth was the most important determinant of the LBW. According to the results, $33.1 \%$ of the babies born were small for gestational age whereas appropriate for gestational agewere $66.9 \%$. LBW frequency decreases with the increase in the maternal education. $18 \%$ of LBW babies mother were uneducated. $12 \%$ were educated and were less likely to deliver LBW infants. Further it was found that as the level of education of mother increases, the occurrence of the LBW successively decreases i.e. $64 \%$ were educated up to primary, $22 \%$ were qualified up to secondary, $12 \%$ were qualified to Higher Level of education. The above statistics could be due to the reason that uneducated mother is uninformed about the prenatal care, nutritional requirements during pregnancy, essential diet, and about the effects of maternal behavior on fetus. Mal-nutrition during pregnancy leads to the occurrence of LBW babies. It was evident from analysis that mothers from lower economic status were more likely to have LBW newborn than those who came from higher social class. The mother with low economic status were $49.3 \%$ and were at higher risk of delivering LBW baby (Table 3). As the socioeconomic level increases the occurrence of the LBW decreases. These statistics could be due to the reason that mother in higher socioeconomic class were having healthy surroundings and had healthy diet to produce heavier babies whereas the mothers in deprived socioeconomic level i.e. unhygienic environment and improper diet were at higher risk of having a low birth weight baby which was similar to the study done by Karim et al. $(1997)^{30}$.

The study showed that age of mother was directly proportionate to deliveries associated with LBW.Most of

\section{References}

1. UNICEF/WHO. Low Birth Weight: country, regional and global estimates. New York: UNICEF; 2004.

2. Save the Children, USA. Saving new born lives: State of the World's Newborns. USA: Save the Children; 2001.

3. Lawn JE, Cousens S, zupan J. Lancet Neonatal Survival Steering Team. 4 million neonatal deaths: when? Where? Why? Lancet 2005;365:891-900.SS

4. Haque F, Hussaian AM: Detection of low birth weight babies by anthropometric measurements in Bangladesh. Indian J Pediatr 1991;58: 223-31.

5. Sood SL, Saiprasad GS, Wilson CG. Mid arm circumference at birth: a screening method for detection of low birth weight. Indian J Pediatr 2002;39: 838-842. the mother of LBW babies in this study belonged to the age $<20$ and $\geq 35 \mathrm{yrs}(p$-value $<0.05)$ which was similar to study done by Khatun et al. (2008) ${ }^{26}$. The incidence of LBW was higher among smoker mother as compared to non-smoker mothers $(72.75 \%$ vs $30.5 \%$ respectively). Maternal alcohol intake during or prior to the pregnancy and its association with LBW was also studied and was significantly associated with LBW. This finding was similar to study done by Dickute et al. $(2002)^{29}$.

Our study also showed that regular antenatal visit is very important in reducing various complications during pregnancy including the birth weight of a neonate. It showed the positive effect on number of antenatal care visit on birth weight. Those mothers who received 4 or more antenatal care gave birth to higher birth weight in comparison to mothers who received 2 or less antenatal care visit $(25.0 \%$ vs $94.3 \%$ respectively) with $p$-value $<0.05$.

\section{Conclusion}

The present study shows that Birth weight is a major determinant of health as well as morbidity, mortality and disability in neonates, childhood and also later life. This study suggests several factors interplay determining the birth weight of a newborn.Socio-demographic factors (maternal age, educational level and economic status) and antenatal care are more important.Hence, it is prudent to identify the risk factors causing LBW in neonates and manage them promptly and also knowledge about the socio-economicdeterminants of LBW could lead to a better evidence based interventions at reducing neonatal mortality in Nepal.

6. WHO. Perinatal mortality: a listing available information. FRH/MSM.96.7.Geneva:WHO; 1996

7. UNICEF. The state of the world's children. New York: UNICEF; 2005.

8. Bang A, Reddy MH, Deshmukh MD. Child mortality in Maharashtra. Eco Polit Weekly 2002;37: 4947-65.

9. Diamond I, Mc Donald J. Use of simple anthropometric measurement to predict Birth Weight. Bull WHO 1993; 71:157-163.

10. Cormic MC. The contribution of low birth weight to infant mortality and childhood morbidity. $N$ Engl $J$ Med1985;312: 82-89.

11. MIRA and UNICEF. Low birth weight prevalence and associated factors in four regions of Nepal 2000.

12. Population Division, Ministry of Health and Population, Government of Nepal. Demographic and Health Survey 2006. Kathmandu, Nepal; 2007. 
13. Berkowitz GS, Papiemik E. Epidemiology of preterm birth. Epidemol Rev 1993;15:414-43.

14. Dunin -Wasowicz D, Rowecka K, Milewaska BB, Kassur-Siemienska B, Lipika B. Risk factors foe cerebral palsy in very low birth weight infants in the 1980s and 1990s. J Child Neurol 2002;15:414-20.

15. Barker DJP, Forsen T, Uutela A, Osmond C, Eriksson JG. Size at birth and resilience to effects of poor living conditions in adult life: Longitidunal Study. $\mathrm{Br} \mathrm{Med} \mathrm{J}$ 2001;323: 1273-76.

16. Eriksson JG, Forsen $\mathrm{T}$, Tuomiletho $\mathrm{J}$, winter $\mathrm{PD}$, Osmond C, Barker DJP. Catch up growth in childhood and death from coronary heart disease: Longitudinal study. Br Med J 1999;318:427-31

17. Lynch JW, Kaplan GA. Socioeconomic factors. In: Berkman LF, Kawachi I editor. Social epidemiology. New York: 2000.p.13-35.

18. Marmot MG,Shipley MJ. Do socio-economic differences in mortality persist after retirement? 25 years follow up of civil servants from the first whitehall study. Br Med J 1996;313:1177-80.

19. WadworthM.Early life in social determinants of health. In: Marmot M, Wilkinson RG, editors. Social determinants of heath. Denmark:Oxford University Press; 1999. p.44-52.

20. Coria-Soto I, Bobadilia J, Notzen F. The effectiveness of antenatal care in preventing intrauterine growth retardation and low birth weight due to preterm delivery. Int J Qual Health Care 1996;8:13-20.

21. WHO publications available at: http/www.who.int/ reproductivehealth/publications/RHR01 30.

22. Kennedy BP, Kawachi I, Glass R, Prothrow-Stith D. Income distribution, socioeconomic status and self rated health in the United States: Multilevel analysis. Br Med J 1998:317:917-21.

23. Kramer S. Determinants of low birth weight: Methodological assessment and meta-analysis.Bull WHO 1987;65:663-737.

24. Johnston LB, Clark AJL, Savage MO. Genetic Factor Contributing to Birth Weight.Arch Dis in Child(Fetal and Neonatal Ed) 2002;86:F2-F3.

25. Stephenson $\mathrm{T}$, Symonds ME. Maternal nutrition as a determinant of birth weight. Arch Dis in Child(Fetal and Neonatal Ed) 2002;86:F4-F6.

26. Khatun S, Rahman M. Socio-economic determinants of low birth weight in Bangladesh: A multivariate approach. Bangladesh Med Res Counc Bull 2008;34:81-86.

27. Tuntiseranee $P$, Olsen J, Chongsuvivatwong V, Limbutara S. Socioeconomic and work related determinants of pregnancy outcome in southern Thailand. Epidemiol Community Health 1999;53:62429.

28. Elshibly EM, Schmalisch G. The effect of maternal anthropometric characteristics and social factors on gestational age and birth weight in Sudanese newborn infants. BMC Public Health 2008;8:244.

29. Dickute J, Padaiga Z, Grabbauskas V, Gaizauskiene A, Basyas V, Obelenis V. Do maternal social, health behaviour and working conditions during pregnancy increase the risk of low birth weight in Lithuania? Medicina 2002;38:321-32.

30. Karim E, Mascie-Taylor CGN. The association between birthweight, socio-demographic variables and maternal anthropometry in an urban sample from Dhaka, Bangladesh. Annals HumBio/1997;24:387-401. 